\title{
NOTES
}

\section{FIRST DOCUMENTATION OF SUCCESSFUL BREEDING FOR THE ANNA'S HUMMINGBIRD IN IDAHO}

BRYCE W. ROBINSON, Cornell Lab of Ornithology, Cornell University, Ithaca, New York 14850; bwr46@cornell.edu

JESSICA J. POLLOCK, HEIDI WARE CARLISLE, and HEATHER M. HAYES, Intermountain Bird Observatory, Boise State University, Boise, Idaho 83725

JANICE ENGLE, 3046 E. Stone Point Dr., Boise, Idaho 83712

Currently, the Anna's Hummingbird (Calypte anna) breeds along the west coast of North America from Baja California to British Columbia and east into inland areas of California, Arizona, New Mexico, Oregon, and Washington (Clark and Russell 2012). The current distribution is a result of 80 years of range expansion out of Baja and coastal California, largely facilitated by urbanization, landscaping with non-native plants, and supplementary feeding (Greig et al. 2017, Battey 2019). Pollock et al. (2021), summarizing the recent increase in the numbers wintering in Idaho, illustrated that the species' range continues to expand. This increase in winter numbers over time mirrors the trend in Arizona in the 1960s, when the establishment of a breeding population followed wintering (Zimmerman 1973, Clark and Russell 2012). Pollock et al. (2021) further suggest that Anna's Hummingbird may now be a sparse year-round resident in parts of Idaho, primarily the greater Boise metropolitan area. Given the recent trend in Idaho that includes an increase in summer numbers in the past three years (ibid.), the establishment of a breeding population in the state seems possible, even probable.

Rudeen and Bassett (2016) presented evidence implying that Anna's Hummingbird has already bred in Idaho: the captures of multiple individuals in juvenile plumage in August, a gravid female at the same location in two consecutive seasons, and a putative hybrid male Anna's $\times$ Calliope Hummingbird. Given this evidence, they reasonably expected documentation of nesting to be imminent.

On 14 July 2020, Engle discovered an adult female Anna's Hummingbird attending a nest containing two nestlings in the front yard of her home in the Warm Springs Mesa neighborhood in southeast Boise (Figure 1). The nest was situated on a horizontal limb of a Rose of Sharon tree (Hibiscus syriacus), 3 m high and only 2 $\mathrm{m}$ from the front window of the home. Engle's home sits at $930 \mathrm{~m}$ elevation, in an urban neighborhood adjacent to the foothills, and with a landscaped yard including a fountain, pond, multiple flowering plants, and hummingbird feeders. We monitored the nest daily until the nestlings began to climb from the nest on 17 July (Figure 2). Both young fledged successfully on the morning of 18 July.

Following the fledging of the young, we attempted to capture the adult and fledglings at Engle's feeders. Unfortunately, we were able to capture only the adult female, which we discovered was banded (see M07787 in Table 1 in Pollock et al. 2021). This female was first captured and banded on 25 January 2019 at a home 0.5 $\mathrm{km}$ from the location where she nested at Engle's home. She was recaptured the following winter on 17 December 2019 at the same location, and is among a growing number of individuals whose site fidelity in Idaho over successive winters has been confirmed (see Table 1 in Pollock et al. 2021). Interestingly, the homeowners did not observe her at this location in either summer 2019 or 2020, despite the proximity to the site of her nesting.

The identity of the male parent of these fledglings is unknown. As is general in 


\section{NOTES}

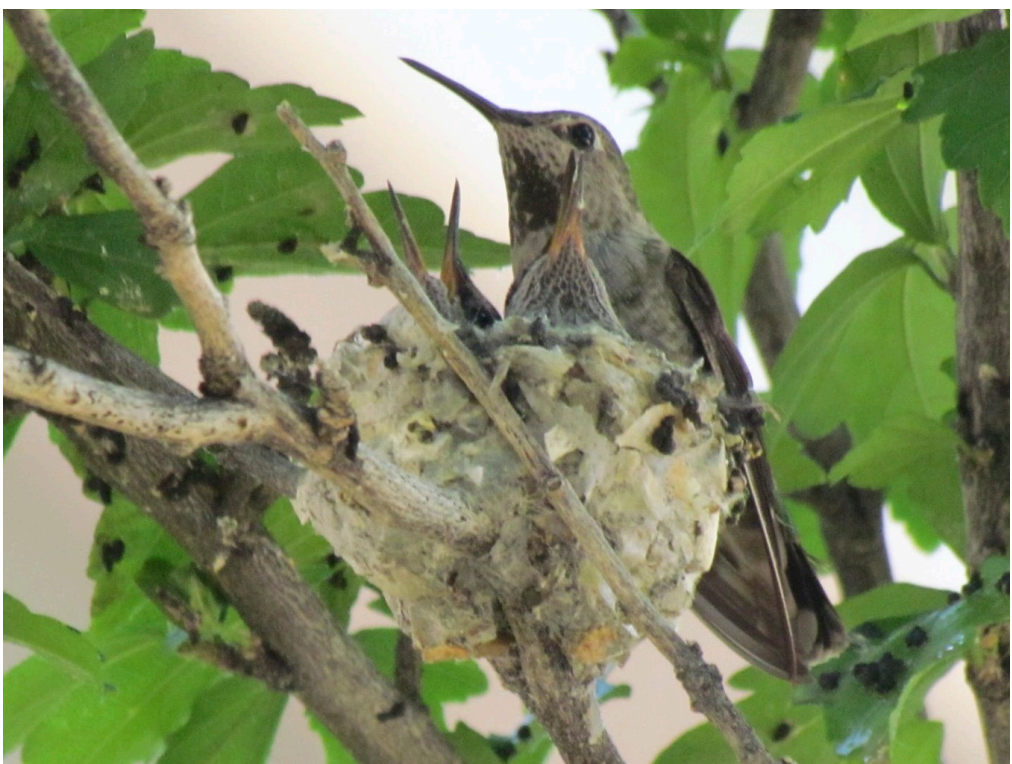

FIGURE 1. Adult female Anna's Hummingbird (Calypte anna) attending two nestlings in southeast Boise, Idaho, 14 July 2020. This photograph represents the first documentation of nesting of the Anna's Hummingbird in Idaho.

Photo by Janice Engle

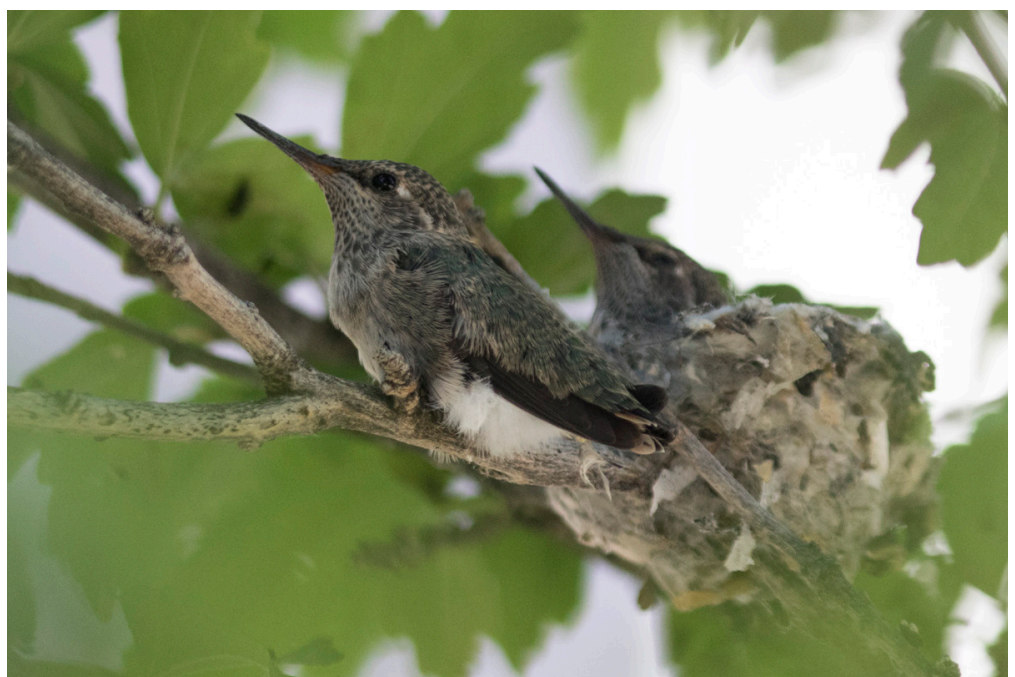

Figure 2. The two nestling Anna's Hummingbirds on 17 July 2020, one day prior to their successful fledging on 18 July. 
hummingbirds, males of $C$. anna are not involved in brood care (Clark and Russell 2012), so it is not surprising we never observed a male in the area following the discovery of the nest. However, Engle did observe an adult male Anna's Hummingbird at her feeders on 7 July, only 7 days before she discovered the nest. Alternatively, it is possible that the female Anna's was paired with a male Black-chinned Hummingbird (Archilochus alexandri), the only hummingbird species that breeds commonly in the Boise metropolitan area. Hybridization between A. alexandri and C. anna has never been directly documented, although multiple birds that fit the expected appearance of this hybrid have been photographed (see Black-chinned $\times$ Anna's Hummingbird at www.macaulaylibrary.org), and there is one specimen record (Banks and Johnson 1961). Nevertheless, from our observations and photographs of the juveniles (Figure 2 ), we assert that these are not a result of hybridization between $C$. anna and $A$. alexandri. We reviewed photographs of fledglings and juveniles of both species available in the Macaulay Library, the detailed plumage descriptions in Howell (2003), and the photographs of nestlings in figure 5 of Greeney et al. (2008) and compared these to photos of the fledglings at Boise. The Boise fledglings differed from juvenile Black-chinned Hummingbirds in being overall duskier in appearance, particularly in the flanks, which had greenish feathers typical of Anna's. The Boise birds also differed from $A$. alexandri in having densely marked throats and relatively dark heads. Although wing shape was difficult to judge in our photos, we noted that the inner primaries were not appreciably narrower than the outer primaries, as is seen in the Black-chinned, and appeared to fit the shapes expected of C. anna. Additionally, the shape of the exposed primaries differed from those shown in figure 5 of Greeney et al. (2008), appearing relatively straight in the Boise birds and not substantially curved as in the Black-chinned nestlings. Overall, the plumage of the Boise fledglings seemed to fit the Anna's Hummingbird, and did not appear to be intermediate between the two species, as would be expected in first-generation hybrids.

The timing of this nesting is notable. Throughout its native range, the Anna's Hummingbird breeds from December to May (Clark and Russell 2012). At the margins of its distribution in coastal Washington and British Columbia, nesting begins slightly later, from January to February (ibid.). By taking the average periods of incubation and nestling (16 and 20 days respectively; Clark and Russell 2012) and backdating from the date of fledging on 18 July, we estimate the nest to have been initiated on 12 June, an atypically late date by comparison to the dates reported elsewhere throughout the species' range. Anna's Hummingbirds often raise multiple broods in a single breeding season (Scarfe and Finlay 2001), and this nesting could represent a second brood. The phenology we observed in Idaho is matched by the first reported breeding of the species in southwestern Canada in 1958, which also occurred in July (Campbell et al. 1990). More reporting and continued focus on the species' phenology of nesting at the margins of its range may uncover if the schedule in these two instances is typical for extralimital breeders.

This first documented successful breeding of the Anna's Hummingbird in Idaho provides a marker on the chronology of the species' range expansion into the state. This chronology has thus far been well documented through the methods outlined by Pollock et al. (2021). Continued focus and documentation of the increase in numbers, as well as of further instances of breeding, will provide fine-scale details to the ongoing range expansion experienced by this species since the urbanization of the West accelerated in the middle of the 20th century. Investigations into the provenance of Anna's Hummingbirds wintering around Boise will provide further clarity to the pattern of expansion into Idaho, and elsewhere.

We thank David Towner who initially reported M07787, the nesting female, in his yard in December 2018, through the Intermountain Bird Observatory's communityscience program of hummingbird reporting. We also thank Jay Carlisle, Daniel D. Gibson, and Chris Clark for their helpful reviews of the manuscript. 


\section{NOTES}

\section{LITERATURE CITED}

Banks, R. C., and Johnson, N. K. 1961. A review of North American hybrid hummingbirds. Condor 63:3-28; doi.org/10.2307/1365419.

Battey, C. J. 2019. Ecological release of the Anna's Hummingbird during a northern range expansion. Am. Nat. 194:306-315; doi.org/10.1086/704249.

Campbell, R. W., Dawe, N. K., McTaggart-Cowan, I., Cooper, J. M., Kaiser, G. W., and McNall, M. C. E. 1990. The Birds of British Columbia, vol. 2. Royal Br. Columbia Mus., Victoria.

Clark, C. J., and Russell, S. M. 2012. Anna's Hummingbird (Calypte anna), in The Birds of the North America (A. F. Poole, ed.), no. 226. Cornell Lab Ornithol., Ithaca, NY; doi.org/10.2173/bow.annhum.01.

Greeney, H. F., Hough, E. R., Hamilton, C. E., and Wethington, S. M. 2008. Nestling growth and plumage development of the Black-chinned Hummingbird (Archilochus alexandri) in southeastern Arizona. Huitzil 9:35-42; doi.org/10.28947/ hrmo.2008.9.2.78.

Greig, E. I., Wood, E. M., and Bonter, D. N. 2017. Winter range expansion of a hummingbird is associated with urbanization and supplementary feeding. Proc. Royal Soc. B: Biol. Sci. 284:20170256; doi.org/10.1098/rspb.2017.0256.

Howell, S. N. G. 2003. Hummingbirds of North America: The Photographic Guide. Princeton Univ. Press, Princeton, NJ.

Pollock, J. J., Carlisle, H. W., Hayes, H. M., and Robinson, B. W. 2021. Monitoring through community science: Anna's Hummingbird winter range expansion into Idaho. W. Birds 52:58-67.

Rudeen, C., and Bassett, F. 2016. Apparent breeding by Anna's Hummingbird in Idaho. W. Birds 47:237-241; doi.org/10.21199/WB47.3.6.

Scarfe, A., and Finlay, J. C. 2001. Rapid second nesting by Anna's Hummingbird near its northern breeding limits. W. Birds 32:131-133.

Zimmerman, D. A. 1973. Range expansion of Anna's Hummingbird. Am. Birds 27:827-835. 